\title{
Molecular genetics of peripheral T-cell lymphomas
}

\author{
Pier Paolo Piccaluga • Valentina Tabanelli • \\ Stefano A. Pileri
}

Received: 10 January 2014/ Accepted: 15 January 2014/Published online: 31 January 2014

(c) The Japanese Society of Hematology 2014

\begin{abstract}
Peripheral T-cell lymphomas (PTCL) are rare neoplasms that in most instances respond poorly to conventional chemotherapies. Four varieties-PTCL not otherwise specified (NOS), angioimmunoblastic T-cell lymphoma (AITL), ALK+ anaplastic T-cell lymphoma (ALCL), and ALK - ALCL-account for about $60 \%$ of them. Their classification is difficult because of the wide spectrum of morphologic features and the lack of robust immunohistochemical markers. Thus, high-throughput technologies can importantly contribute to their better understanding. In particular, gene expression profiling has cleared the borders among PTCL/NOS, ALK - ALCL and AITL. In fact, gene signatures have been developed even from formalin-fixed paraffin-embedded tissue samples that definitely distinguish one tumor from the other(s). This has important practical implications: for instance on routine diagnostics PTCL/NOS expressing CD30 can be easily confused with ALK - ALCL, but has a much worse prognosis. Therefore, the clear-cut distinction between the two conditions is pivotal to understand the results of ongoing trials with Brentuximab Vedotin, targeting the CD30 molecule. Besides improving the diagnosis, molecular studies have provided the rationale for the usage of novel drugs in the setting of PTCLs, such as ALK inhibitors in ALK+ ALCL, anti-angiogenetic drugs in AITL, and tyrosine kinase inhibitors in PTCL/NOS and ALK+ and ALK - ALCLs.
\end{abstract}

P. P. Piccaluga $(\bowtie) \cdot$ V. Tabanelli · S. A. Pileri

Hematopathology Unit, Department of Experimental, Diagnostic, and Specialty Medicine, S. Orsola-Malpighi Hospital, Pavillon 8, Bologna University Medical School, Via Massarenti, 9, 40138 Bologna, Italy

e-mail: pierpaolo.piccaluga@unibo.it
Keywords Peripheral T-cell lymphomas - Tyrosine kinases · High-throughput sequencing · Gene expression profiling

\section{Background}

Peripheral T-cell lymphomas (PTCL) are rare tumors derived from mature T-lymphocytes with different functional properties (e.g., cytotoxic, helper, regulatory, and follicular helper) and NK cells. They account for approximately $10 \%$ of all lymphomas being relatively common in Asia and definitely rarer in Western Countries [1-3]. Each year, approximately 9500 new cases are diagnosed in Europe [ECO/IARC]. They affect more often adults and elderly people, the median age at onset being around 64 years. They are among the more aggressive lymphomas with cure rates below $30 \%$ [4]. However, it should be noted that under the term "PTCL" a series of eighteen distinct entities and a few provisional ones are recorded in the last edition of the WHO classification. Indeed, while some of them are provided with a relatively good prognosis (i.e., large granular cell leukemia and most cutaneous T-cell neoplasms), others are more often incurable (i.e., nodal PTCLs and NK-tumors).

Among nodal PTCLs, angioimmunoblastic lymphoma (AITL), anaplastic large cell lymphoma (ALCL) ALK+ and ALK - , and the not otherwise specified type (NOS) represent the commonest entities. Importantly, although for many years they have been managed as a unique tumor (with the possible exception of ALK + ALCL, especially in the pediatric setting), recent evidences pointed out that they are distinct on both the pathobiological and clinical ground. In particular, as they are provided with diverse prognosis [4-6], different phenotypic and molecular profiles [6-10], and distinct genetic patterns [11-15], it is reasonable that in the 
near future ad hoc interventions will be adopted. In this regard, very recently Brentuximab Vedotin, a conjugated anti-CD30 monoclonal antibody (MoAb) was approved for the treatment of relapsed/refractory ALCL but not other PTCL subtypes, while clinical trials have been designed for specific subtypes [16], many of which are currently ongoing.

In this article the Authors, based on their own experience and the literature data, will review the current knowledge on nodal PTCL biology with special reference to molecular genetics as possible basis for targeted treatments.

\section{Molecular pathology of ALCL}

ALCL is an aggressive but curable tumor characterized by hallmark large cells and consistent CD30 expression [17].

ALCL has been the first PTCL for which a recurrent, pathogenetic lesion has been recognized, namely, the $\mathrm{t}(2 ; 5)(\mathrm{p} 23 ; \mathrm{q} 35)$ leading to the fusion of nuclophosmin (NPM1) to the anaplastic lymphoma kinase $(A L K)$ into the $N P M 1 / A L K$ fusion transcript encoding for the corresponding chimeric protein [17]. Later on, variants of such translocation have been discovered, all leading to ALK overexpression $[18,19]$. Of note, ALK expression currently defines a specific clinic-pathological entity [20]. For its diagnosis, the recognition of either the genetic lesion or the ALK protein expression pattern can be applied.

In the last decade, the pathogenetic effects of ALK have been largely studied. In particular, it has been demonstrated that ALK is necessary and sufficient for inducing ALCL development in vivo [21-23] and that ALK inhibition can be an effective therapeutic strategy [22, 24, 25]. Subsequently, the downstream signaling has been characterized, leading to a better comprehension of ALCL pathogenesis. Of note, ALK-aberrant tyrosine kinase activity enhances cell proliferation and survival, triggering several signaling cascades (including PI3K/AKT/mTOR, JAK/STAT3, RAS/ERK and others). Among them, STAT3 displays a pivotal role in ALCL tumorigenesis: it is constitutively activated by ALK either directly or through Janus kinase 3 (JAK3) and modulates the transcription of both antiapoptotic factors and cell-cycle regulators. STAT3 activation seems to be strictly required for ALK+ ALCL cells survival, since its silencing leads to G1 cell-cycle arrest, followed by apoptotic death, making this transcription factor a potential therapeutic target. STAT3 knockdown is associated with a well-defined modulation of a large number of genes (many of which are downregulated by active p-STAT3); it has been proposed that some of these genes may be used as diagnostic tools to discriminate ALCL from PTCL, NOS $[2,8,18,22]$. As ALK deregulation is the key pathogenetic event in ALK+ ALCL, targeting ALK is an ideal therapeutic strategy. So far, however, data are relatively limited and further clinical studies are warranted; sensitivity of relapsed, advanced ALK-positive ALCL to crizotinib (an ALK tyrosine kinase inhibitor approved for the treatment of ALK+ non-small cell lung cancer) has been reported in pediatric patients and small case series [26, 27].

On the other hand, it has become clear that CD30 expression is per se a consequence of ALK activity (via RAS/ERK pathway) and in turn determines a downstream signaling that seems to be intricately linked to NF-kB; molecular analysis demonstrated that CD30 stimulation of ALCL cells leads to cell-cycle arrest without induction of apoptosis [28, 29]; while induction of massive cell death is observed when a concomitant nuclear factor $\mathrm{kB}(\mathrm{NF}-\mathrm{kB})$ blockade is established by a NF-kB inhibitor ( $\mathrm{IkBaDN}$ ) [30] or proteasome inhibitor [31].

CD30 expression is uncommon in healthy tissues, and targeting CD30-positive cells may represent a selective treatment strategy; considering that the use of unconjugated anti-CD30 antibodies showed minimal clinical activity [32], research efforts have been leaned mainly toward to antibody-drug conjugates that allow delivery of cytotoxic drugs to cancer cells, sparing CD30-negative tissues [18]. Indeed, Brentuximab Vedotin (an anti-CD30 monoclonal antibody conjugated to an inhibitor of microtubule polymerization) demonstrated to be highly effective even in heavily pretreated patients, and was then approved for the clinical usage $[33,34]$ (Fig. 1-ALK signaling).

ALK - ALCL is currently included in the WHO classification as a provisional entity [35]. It is, by definition, indistinguishable from ALK+ forms by both morphology and phenotype and only the detection of ALK allows a correct diagnosis. ALK - ALCL has been for a long time distinguished from the ALK+ type due to its more aggressive clinical course. However, if an age-adjusted analysis is performed, thus excluding the ALK+ cases occurring in children and younger adults, the prognosis of the two tumors does not appear to be strikingly different [5]. On the other hand, ALK - ALCL has to be distinguished by PTCL/NOS. In fact, it is characterized by a more favorable outcome $[5,6]$ and presents with a distinctive molecular profile. In this regard, we recently showed that gene expression profile (GEP) could discriminate ALK- ALCL and PTCL/NOS (including CD30+ cases) with high accuracy, providing prognostic information more efficiently than conventional histopathology [6].

The molecular genetics of ALK - ALCL to date is very poorly understood. Recently, a novel $\mathrm{t}(6 ; 9)(\mathrm{p} 25.3 ; \mathrm{q} 32.3)$ translocation [36] has been identified by high-throughput sequencing (HTS), but its molecular effects remain to be defined. Of note, GEP indicated that STAT3 signaling is active in ALK - ALCL as in the ALK+ cases [8]; this finding possibly suggests that genetic events other than 

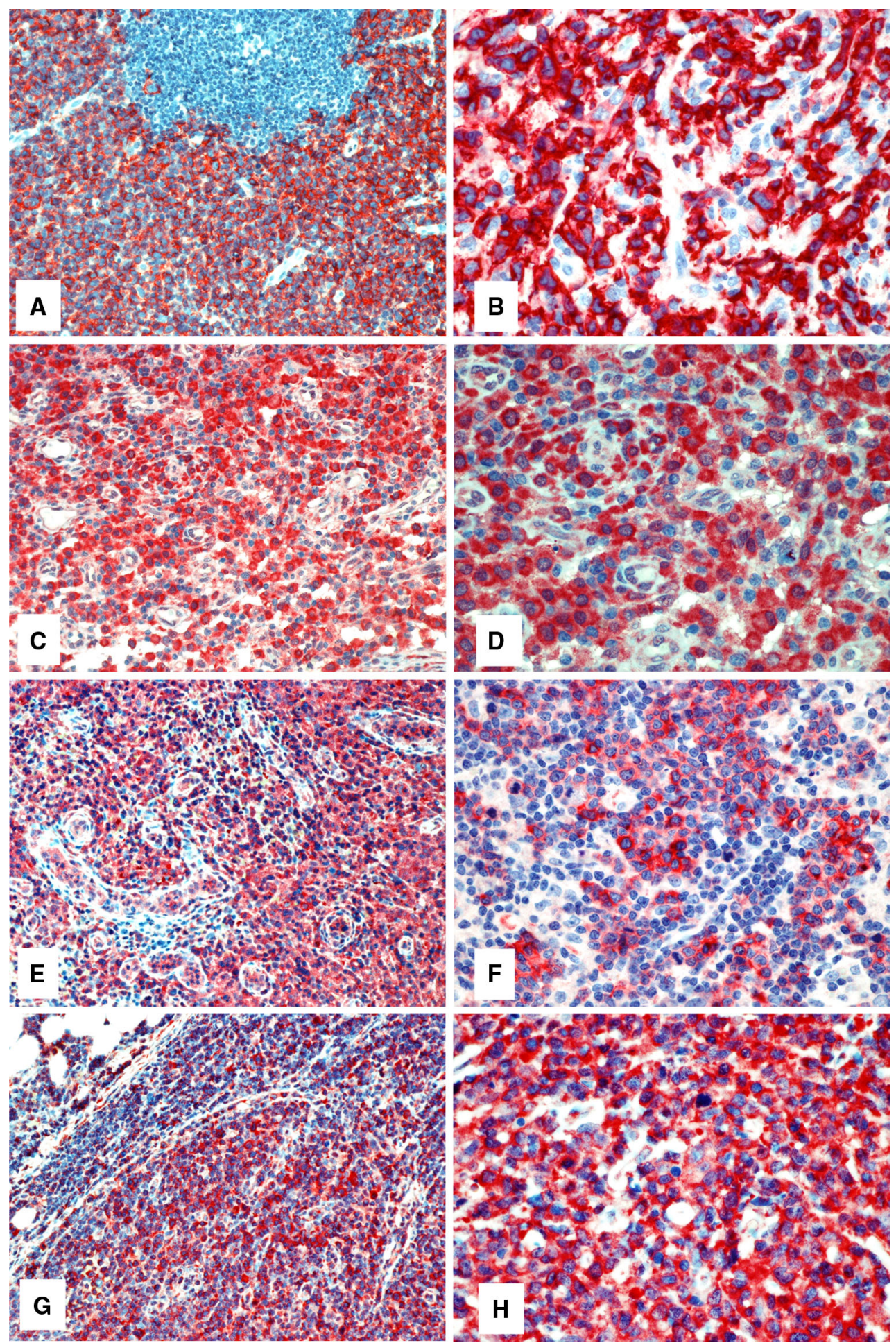

Fig. 1 Immunohistochemical detection of potential therapeutic targets in peripheral T-cell lymphomas. Anaplastic large-cell lymphoma: CD30 $(\times 20, \mathbf{a})$, CD30 $(\times 40, \mathbf{b})$, STAT3 $(\times 20, \mathbf{c})$, and STAT3 $(\times 40$,

d). Angioimmunoblastic lymphoma: VEGFR2/KDR $(\times 20, \mathbf{e})$. Peripheral T-cell lymphoma NOS: CD30 $(\times 40, \mathbf{f})$, PDGFRA $(\times 20, \mathbf{g})$, and PDGFRA $(\times 20, \mathbf{h})$

Interestingly, both ALK+ and ALK- ALCL were ALK rearrangements may occur in ALK - tumors, determining effects similar to those exerted by $t(2 ; 5)$. HTS studies are currently ongoing to solve this issue. shown to present PDGFRs expression, PDGFRB being expressed as a direct effect of ALK signaling through the 
JUNB transcriptional activity. Most importantly, PDGFRs inhibition by imatinib exerted a potent anti-lymphoma effect both experimentally and in clinics [37].

\section{Molecular pathology of AITL}

AITL was first described in 1974 as angioimmunoblastic lymphadenopathy with dysproteinemia [38]. It is clinically characterized by a typical (even though not completely specific for this disease only) clinical syndrome, including B-symptoms, skin rash, and hypergammaglobulinemia as a consequence of a prominent immune reaction. At morphology, AITL is quite characteristic as well, presenting with diffuse lymph node architecture defeating, clear cell cytology, abundant follicular dendritic cell (FDC) hyperplasia, and prominent and complex arborizing vascular structures [39]. Of note, numerous B-lymphocytes are typically observed, sometimes with EBV integration and clonal restriction. Clinically, the disease is quite aggressive and can be further complicated by possible transformation of the clonal EBV+ B-cells into a diffuse large B-cell lymphoma [40-42].

At immunophenotyping, neoplastic cells are $\mathrm{CD} 3+$, $\mathrm{CD} 4+$, and more often lack one of more T-cell associated antigens such as CD5 and CD7 [43]. In addition, in the last few years it has been shown that AITL cells usually carry T-follicular helper (TFH) phenotype, BCL6, CD10, CXCl13, PD1, SAP, and ICOS being variably expressed [43-46]. This is definitely consistent with the evidences emerged form GEP studies, that demonstrated as AITL is closely related to TFH cells [7, 47]. Beside the diagnostic implications (TFH markers can be useful in discriminating AITL from other PTCL types), the derivation from TFH cells may have intriguing pathogenetic implications. In fact, on the one hand, the fact that one of the commonest T-cell tumors derive from one of the rarest $\mathrm{T}$-cell subsets, may suggest that TFH is particularly exposed to the risk of transformation. Of note, they lie within germinal centers, the functional structure from which most B-cell lymphomas derive. On the other hand, TFH is deputed to a close interaction with both B-lymphocytes and FDCs, which is commonly over-represented in AITL cases. It is conceivable that as in physiological conditions these cell types provide trophic signals to each other, the neoplastic clone may obtain beneficial support from the surrounding microenvironment. To test this hypothesis, the GELA group recently designed a clinical trial including rituximab in the treatment of AITL. Even though a preliminary analysis suggested a beneficial effect from the addition of rituximab, the final results did not confirm it [16]. Nonetheless, a functional role of B-cells in the pathogenesis of the disease could not be completely ruled out and further functional studies would be warranted. In this regard, our group recently showed that mast-cells accumulating in AITL may play a significant role as they induce and expand the Th17cell subset (that we found significantly more represented in AITL microenvironment than in PTCL/NOS cases) through IL-6 production; these Th cells are involved as a key factor in the pathogeneses of autoimmunity [48] and their increase may explain the high frequency of autoimmune phenomena occurring in the setting of AITL [49].

GEP analyses also indicated that many genes involved in promoting angiogenesis characterize the molecular signature of AITL. Particularly, VEGF appeared to be involved. Interestingly, despite evidences that VEGF is produced by by-stander non-neoplastic cells [47], we and others clearly demonstrated that VEGF can be produced by neoplastic cells as well $[7,47,50]$. In addition, we demonstrated that AITL cells do also express the VEGFR1/ KDR. Therefore, it is conceivable that VEGF production not only promotes angiogenesis but also directly stimulates tumor growth through an autocrine/paracrine loop. Remarkably, subsequent clinical reports indicated a promising sensitivity of relapsed/refractory AITL patients to drugs provided with antiangiogenic properties such as bevacizumab, thalidomide and lenalidomide [51-54].

More recently, the genetics of AITL has been further explored offering relevant insights into its pathogenesis. In particular, different studies demonstrated a high incidence of somatic mutations in IDH2 (identified in 20 and $47 \%$ of test set and independent set cases, respectively) and TET2 (identified in 40 of 86 AITL cases, $47 \%$ ) genes [12-14]. Both IDH2 and TET2 encode for proteins involved in epigenetic regulation suggesting that disruption of gene expression regulation by methylation and acetylation may be involved in AITL development and or progression. In this regard, a histone deacetylase inhibitor (HDACi), romidepsin, has been recently approved in USA for the treatment of relapsed/refractory PTCLs, including AITL. Consistently, a bioinformatics prediction by Connectivity map [http://www.broadinstitute.org/cmap/] indicated that HDACi could revert the transcriptional profile of AITL that is related to its malignant phenotype (personal observation).

Additional genetic findings include the presence of mutations affecting ROHA small GTPase gene (RHOA G17V) $[55,56]$.

\section{Molecular pathology of PTCL/NOS}

PTCL/NOS is the commonest PTCL, representing roughly $30 \%$ of all cases. It probably encompasses more than one single disease as suggested by the great morphological, phenotypical and genetic heterogeneity. In particular, at morphology, the neoplastic population can include small-, 
medium-, and large-sized cells in variable proportions with more monomorphic (with either small or large cells) or polymorphic patterns. The immunophenotype is typically aberrant with T-cell associated antigens defect and inappropriate $\mathrm{CD} 4 / \mathrm{CD} 8$ expression patterns that do not correspond to the effective functional lineage as demonstrated by GEP $[7,44]$. Of note, more than half of the cases present with significant CD30 expression [10], making the differential diagnosis with ALCL ALK- more challenging and suggesting the possible usefulness of anti-CD30 therapies.

On the other hand, as far as genetic is concerned, it should be noted that only few studies dealt with PTCL/ NOS karyotyping. A few comparative genomic hybridization/SNPs array studies indicated that no recurrent specific lesions could be appreciated, but rather a complex pattern was common [57-59]. Interestingly, a small percentage of cases showed aberrations at the 2p15-16 locus, where REL maps. In these cases, pNF-kB pathway activation could be then documented [57].

Further insights into PTCL/NOS biology were later provided by GEP studies [7, 9, 60-63]. Specifically, GEP demonstrated for the first time that PTCL/NOS could correspond to either helper or cytotoxic lymphocytes, independently from the expression of CD4 and CD8, with possible prognostic implications [7, 9]. Further, it was shown that a fraction of PTCLs/NOS had a molecular profile related to those of TFH, similarly to AITL [47]. Interestingly, a significant percentage of TFH-related PTCL/NOS presents the same mutation pattern of AITL (IDH2 and TET2); however, based on GEP they are distinct from AITL, this extending the spectrum of TFH-related neoplasm to at least two different PTCL types. In support of this hypothesis, a recurrent $\mathrm{t}(5 ; 9)(\mathrm{q} 33 ; \mathrm{q} 22)$ translocation, leading to SYK overexpression and activation, has been described in follicular PTCL (that present a TFH phenotype) but not in AITL [64, 65].

In addition, despite the global heterogeneity of PTCL/ NOS, GEP indicated that a series of genes and cellular programs are consistently deregulated in most instances. Among others, the tyrosine kinase receptor PDGFRA turned out to be commonly overexpressed and activated in virtually all cases. Interestingly, PDGFRA signaling is not sustained by primary genetic lesions of the gene, but rather by autocrine stimulation. Recently, evidences that PDGFRs inhibition can be an effective strategy for PTCL/NOS therapy were also reported $[37,66]$, opening a new scenario in this setting. Of note, other PTCL types, including NK-derived tumors, do share this feature [7, 64].

As far as the new possible therapeutic strategies are concerned, GEP also showed that abnormalities in the molecular profile of PTCL/NOS were compatible with epigenetic deregulation [7]. Accordingly, HDACi were found to be effective ex vivo [7] and later on were approved for the treatment of relapsed/refractory patients in USA [67]. Further, consistent expression of Aurora kinase A was recently reported [68-71] and specific trials with Aurora kinase inhibitors have initiated.

More recently, as high-throughput sequencing techniques have become available, efforts have been made to uncover the genetic bases of PTCL/NOS. However, so far no highly recurrent lesions were identified, confirming the genetic heterogeneity of the disease. On the other hand, some specific pathways seemed to be particularly affected, including $F Y N$, WNT/B-Catenin (APC, CHD8, and CELSR2), NOTCH (NOTCH1 and FBXW7), and NF-kB (TNFAIB3), based on very recent preliminary reports $[15$, 72]. Perhaps, the integration of GEP data with mutational ones will be of help in defining genetic subgroups with recurrent lesions and well-defined expression profiles.

\section{Conclusion}

In conclusion, emerging evidences support the concept that the commonest nodal PTCL types (AITL, ALCL ALK+ and ALK - and PTCL/NOS) have distinct pathobiological [73] and clinical features. As common pathogenetic pathways could be identified, similar approaches in different subtypes are possible as in the case of many B-cell lymphomas (e.g., BCR-signaling and NF-kB inhibition, or CD20 targeting). However, PTCLs need to be considered as separate entities when clinical trials are designed and specific targets should be also tested at the clinical level. Prospectively, the integration of all available genomic data will probably better define these diseases offering new opportunities to a significant number of lymphoma patients.

Acknowledgments This work was supported by the Centro Interdipartimentale per la Ricerca sul Cancro "G. Prodi", BolognAIL, AIRC (IG4987; IG10519; 10007 5xMille; IG 2013 N.14355), RFO (Prof. Pileri and Prof. Piccaluga), Fondazione Cassa di Risparmio in Bologna, Fondazione della Banca del Monte e Ravenna, Progetto Strategico di Ateneo 2006 (Prof. Pileri and Prof. Piccaluga), and FIRB Futura 2011 RBFR12D1CB (Prof. Piccaluga).

Conflict of interests The authors have no conflicting financial interests to declare.

\section{References}

1. Jaffe ES, Harris NL, Stein H, Campo E, Pileri SA, Swerdlow SH. Introduction and overview of the classification of the lymphoid neoplasms. In: Swerdlow S, et al., editors. WHO classification of tumors of hematopoietic and lymphoid tissues. Lyon: International Agency For Research On Cancer; 2008. p. 158-66.

2. Pileri SA, Piccaluga PP. New molecular insight into peripheral T cell lymphomas. J Clin Invest. 2012;122:3448-55. 
3. Agostinelli C, Piccaluga PP, Went P, Rossi M, Gazzola A, Righi S, et al. Peripheral T cell lymphoma, not otherwise specified: the stuff of genes, dreams and therapies. J Clin Pathol. 2008;61:1160-7.

4. Vose J, Armitage J, Weisenburger D. International T-Cell Lymphoma Project. International peripheral T-cell and natural killer/ T-cell lymphoma study: pathology findings and clinical outcomes. J Clin Oncol. 2008;26:4124-30.

5. Savage KJ, Harris NL, Vose JM, Ullrich F, Jaffe ES, Connors JM, Rimsza L, Pileri SA, et al. International Peripheral T-Cell Lymphoma Project. ALK- anaplastic large-cell lymphoma is clinically and immunophenotypically different from both ALK+ ALCL and peripheral T-cell lymphoma, not otherwise specified: report from the International Peripheral T-cell Lymphoma Project. Blood. 2008;111:5496-504.

6. Piccaluga PP, Fuligni F, De Leo A, Bertuzzi C, Rossi M, Bacci F, et al. Molecular profiling improves classification and prognostication of nodal peripheral T-cell lymphomas: results of a phase III diagnostic accuracy study. J Clin Oncol. 2013;31:3019-25.

7. Piccaluga PP, Agostinelli C, Califano A, Carbone A, Fantoni L, Ferrari S, et al. Gene expression analysis of angioimmunoblastic lymphoma indicates derivation from $\mathrm{T}$ follicular helper cells and vascular endothelial growth factor deregulation. Cancer Res. 2007;67:10703-10.

8. Piva R, Agnelli L, Pellegrino E, Todoerti K, Grosso V, Tamagno $\mathrm{I}$, et al. Gene expression profiling uncovers molecular classifiers for the recognition of anaplastic large-cell lymphoma within peripheral T-cell neoplasms. J Clin Oncol. 2010;28:1583-90.

9. Iqbal J, Weisenburger DD, Greiner TC, Vose JM, McKeithan T, Kucuk C, et al. Molecular signatures to improve diagnosis in peripheral T-cell lymphoma and prognostication in angioimmunoblastic T-cell lymphoma. International Peripheral T-Cell Lymphoma Project. Blood. 2010;115:1026-36.

10. Sabattini E, Pizzi M, Tabanelli V, Baldin P, Sacchetti CS, Agostinelli $\mathrm{C}$, et al. CD30 expression in peripheral T-cell lymphomas. Haematologica. 2013;98:e81-2.

11. Tabbò F, Ponzoni M, Rabadan R, Bertoni F, Inghirami G, European T-cell Lymphoma Study Group. Beyond NPM-anaplastic lymphoma kinase driven lymphomagenesis: alternative drivers in anaplastic large cell lymphoma. Curr Opin Hematol. 2013;20:374-81.

12. Lemonnier F, Couronné L, Parrens M, Jaïs JP, Travert M, Lamant $\mathrm{L}$, et al. Recurrent TET2 mutations in peripheral T-cell lymphomas correlate with TFH-like features and adverse clinical parameters. Blood. 2012;120:1466-9.

13. Cairns RA, Iqbal J, Lemonnier F, Kucuk C, de Leval L, Jais JP, et al. IDH2 mutations are frequent in angioimmunoblastic T-cell lymphoma. Blood. 2012;119:1901-3.

14. Odejide O, Weigert O, Lane AA, Toscano D, Lunning MA, Kopp $\mathrm{N}$. A targeted mutational landscape of angioimmunoblastic $\mathrm{T}$ cell lymphoma. Blood. 2013 (Epub ahead of print).

15. Schatz JH, et al. 55th ASH annual meeting and exposition. Blood. 2013;122:843.

16. Delfau-Larue MH, de Leval L, Joly B, Plonquet A, Challine D, Parrens M, Delmer A. Targeting intratumoral B cells with rituximab in addition to CHOP in angioimmunoblastic T-cell lymphoma. A clinicobiological study of the GELA. Haematologica. 2012;97:1594-602.

17. Morris SW, Kirstein MN, Valentine MB, Dittmer KG, Shapiro DN, Saltman DL, Look AT. Fusion of a kinase gene, ALK, to a nucleolar protein gene, NPM, in non-Hodgkin's Lymphoma. Science. 1994;263:1281-4.

18. Inghirami G, Pileri SA, European T-Cell Lymphoma Study Group. Anaplastic large-cell lymphoma. Semin Diagn Pathol. 2011;28:190-201 (Review).

19. Barreca A, Lasorsa E, Riera L, Machiorlatti R, Piva R, Ponzoni M, European T-Cell Lymphoma Study Group, et al. Anaplastic- lymphoma kinase in human cancer. $\mathrm{J}$ Mol Endocrinol. 2011;47:R11-23.

20. Delsol G, Jaffe ES, Falini B, Gascoyne RD, Muller-Hermelink HK, Stein H, Campo, et al. Anaplastic large cell lymphoma (ALCL), ALK-positive. In: Swerdlow S et al., editors. WHO classification of tumors of hematopoietic and lymphoid tissues. Lyon, France: International Agency For Research On Cancer; 2008. p. $312-16$.

21. Chiarle R, Simmons WJ, Cai H, Dhall G, Zamo A, Raz R, et al. Stat3 is required for ALK-mediated lymphomagenesis and provides a possible therapeutic target. Nat Med. 2005;11:623-9.

22. Chiarle R, Voena $C$, Ambrogio $C$, Piva R, Inghirami G. The anaplastic lymphoma kinase in the pathogenesis of cancer. Nat Rev Cancer. 2008; 8:11-23 (Review).

23. Zamo' A, Chiarle R, Piva R, Howes J, Fan Y, Chilosi M, et al. Anaplastic lymphoma kinase (ALK) activates Stat 3 and protects hematopoietic cells from cell death. Oncogene. 2002; 21:1038-47.

24. Chiarle R, Martinengo C, Mastini C, Ambrogio C, D'Escamard $\mathrm{V}$, Forni G, et al. The anaplastic lymphoma kinase is an effective oncoantigen for lymphoma vaccination. Nat Med. 2008;14: 676-80.

25. Piva R, Chiarle R, Manazza AD, Taulli R, Simmons W, Ambrogio $\mathrm{C}$, et al. Ablation of oncogenic Alk is a viable therapeutic approach for anaplastic large-cell lymphomas. Blood. 2006;107:689-97.

26. Mossé YP, Lim MS, Voss SD, Wilner K, Ruffner K, Laliberte J, et al. Safety and activity of crizotinib for paediatric patients with refractory solid tumours or anaplastic large-cell lymphoma: a Children's Oncology Group phase 1 consortium study. Lancet Oncol. 2013;14:472-80.

27. Gambacorti-Passerini C, Messa C, Pogliani EM. Crizotinib in anaplastic large-cell lymphoma. N Engl J Med. 2011;364:775-6.

28. Hubinger G, Muller E, Scheffrahn I, et al. CD30-mediated cell cycle arrest associated with induced expression of p21(CIP1/ WAF1) in the anaplastic large cell lymphoma cell line Karpas 299. Oncogene. 2001;20:590-8.

29. Hirsch B, Hummel M, Bentink S, et al. CD30-induced signaling is absent in Hodgkin's cells but present in anaplastic large cell lymphoma cells. Am J Pathol. 2008;172:510-20.

30. Ansell SM, Horwitz SM, Engert A, Khan KD, Lin T, Strair R, Keler T, et al. Phase I/II study of an anti-CD30 monoclonal antibody (MDX-060) in Hodgkin's lymphoma and anaplastic large-cell lymphoma. J Clin Oncol. 2007;25:2764-9.

31. Boll B, Hansen H, Heuck F, et al. The fully human anti-CD30 antibody 5F11 activates NF-\{kappa\}B and sensitizes lymphoma cells to bortezomib-induced apoptosis. Blood. 2005;106:1839-42.

32. Tian ZG, Longo DL, Funakoshi S, et al. In vivo antitumor effects of unconjugated CD30 monoclonal antibodies on human anaplastic large-cell lymphoma xenografts. Cancer Res. 1995;55: 5335-41.

33. Forero-Torres A, Leonard JP, Younes A, Rosenblatt JD, Brice P, Bartlett NL, et al. A phase II study of SGN-30 (anti-CD30 mAb) in Hodgkin lymphoma or systemic anaplastic large cell lymphoma. Br J Haematol. 2009;146:171-9.

34. Younes A, Bartlett NL, Leonard JP, Kennedy DA, Lynch CM, Sievers EL, et al. Brentuximab vedotin (SGN-35) for relapsed CD30-positive lymphomas. N Engl J Med. 2011;363:1812-21.

35. Mason DY, Harris NL, Delsol G, Stein H, Campo E, Kinney MC, et al. Anaplastic large cell lymphoma (ALCL), ALK-negative. In: Swerdlow S, et al., editors. WHO classification of tumors of hematopoietic and lymphoid tissues. Lyon: International Agency For Research On Cancer; 2008. p. 317-9.

36. Feldman AL, Dogan A, Smith DI, Law ME, Ansell SM, Johnson $\mathrm{SH}$, et al. Discovery of recurrent $\mathrm{t}(6 ; 7)(\mathrm{p} 25.3 ; \mathrm{q} 32.3)$ translocations in ALK-negative anaplastic large cell lymphomas by massively parallel genomic sequencing. Blood. 2011;117:915-9. 
37. Laimer D, Dolznig H, Kollmann K, Vesely PW, Schlederer M, Merkel O, et al. PDGFR blockade is a rational and effective therapy for NPM-ALK-driven lymphomas. Nat Med. 2012;18:1699-704.

38. Frizzera G, Moran E, Rappaport H. Angio-immunoblastic lymphadenopathy with dysproteinemia. Lancet. 1974;1:1070-3.

39. Dogan A, Gaulard P, Jaffe E, Ralfkiaer E, Muller-Hermelink H, et al. Angioimmunoblastic T-cell lymphoma. In: Swerdlow S, et al., editors. WHO classification of tumors of hematopoietic and lymphoid tissues. Lyon: International Agency For Research On Cancer; 2008. p. 309-31.

40. Abruzzo LV, Schmidt K, Weiss LM, et al. B-cell lymphoma after angioimmunoblastic lymphadenopathy: a case with oligoclonal gene rearrangements associated with Epstein-Barr virus. Blood. 1993;82:241-6.

41. Matsue K, Itoh M, Tsukuda K, Kokubo T, Hirose Y. Development of Epstein-Barr virus-associated B cell lymphoma after intensive treatment of patients with angioimmunoblastic lymphadenopathy with dysproteinemia. Int J Hematol. 1998;67: 319-29.

42. Lome-Maldonado C, Canioni D, Hermine O, et al. Angio-immunoblastic $\mathrm{T}$ cell lymphoma (AILD-TL) rich in large B cells and associated with Epstein-Barr virus infection: a different subtype of AILD-TL? Leukemia. 2002;16:2134-41.

43. Dorfman DM, Brown JA, Shahsafaei A, Freeman GJ. Programmed death-1 (PD-1) is a marker of germinal center associated $\mathrm{T}$ cells and angioimmunoblastic T-cell lymphoma. Am J Surg Pathol. 2006;30:802-10.

44. Went P, Agostinelli C, Gallamini A, Piccaluga PP, Ascani S, Sabattini E, et al. Marker expression in peripheral T-cell lymphoma: a proposed clinical-pathologic prognostic score. J Clin Oncol. 2006;24:2472-9.

45. Krenacs L, Schaerli P, Kis G, Bagdi E. Phenotype of neoplastic cells in angioimmunoblastic T-cell lymphoma is consistent with activated follicular B helper T cells. Blood. 2006;108:1110-1.

46. Roncador G, Garcia Verdes-Montenegro JF, Tedoldi S, Paterson JC, Klapper W, Ballabio E, et al. Expression of two markers of germinal center T cells (SAP and PD-1) in angioimmunoblastic T-cell lymphoma. Haematologica. 2007;92:1059-66.

47. de Leval L, Rickman DS, Thielen C, Reynies Ad, Huang YL, Delsol G, et al. The gene expression profile of nodal peripheral T-cell lymphoma demonstrates a molecular link between angioimmunoblastic T-cell lymphoma (AITL) and follicular helper T cells (TFH). Blood. 2007;109:4952-63.

48. Miossec P, Korn T, Kuchroo VK. Interleukin-17 and type 17 helper T cells. N Engl J Med. 2009;361:888-98.

49. Tripodo C, Gri G, Piccaluga PP, Frossi B, Guarnotta C, Piconese $\mathrm{S}$, Franco G, et al. Mast cells and Th17 cells contribute to the lymphoma-associated pro-inflammatory microenvironment of angioimmunoblastic T-cell lymphoma. Am J Pathol. 2010;177: 792-802.

50. Zhao WL, Mourah S, Mounier N, Leboeuf C, Daneshpouy ME, Legrès $\mathrm{L}$, et al. Vascular endothelial growth factor-A is expressed both on lymphoma cells and endothelial cells in angioimmunoblastic T-cell lymphoma and related to lymphoma progression. Lab Invest. 2004;84:1512-9.

51. Bruns I, Fox F, Reinecke P, Kobbe G, Kronenwett R, Jung G, Haas R. Complete remission in a patient withrelapsed angioimmunoblastic T-cell lymphoma following treatment with bevacizumab. Leukemia. 2005;19:1993-5.

52. Strupp C, Aivado M, Germing U, Gattermann N, Haas R. Angioimmunoblastic lymphadenopathy (AILD) mayrespond to thalidomide treatment: two case reports. Leuk Lymphoma. 2002;43:133-7.

53. Dogan A, Ngu LS, Ng SH, Cervi PL. Pathology and clinical features of angioimmunoblastic T-cell lymphoma after successful treatment with thalidomide. Leukemia. 2005;19:873-5.
54. Dueck GS, Chua N, Prasad A, Stewart D, White D, van der Jagt $\mathrm{R}$, et al. Activity of lenalidamide in a phase II trial for T-cell lymphoma: report on the first 24 cases. J Clin Oncol. 2009; 27:439s (suppl; abstr 8524).

55. Sakata-Yanagimoto $\mathrm{M}$, et al. 55th ASH annual meeting and exposition. Blood. 2013;122:815.

56. Palomero $\mathrm{T}$, et al. 55th ASH annual meeting and exposition. Blood. 2013;122:846.

57. Hartmann S, Gesk S, Scholtysik R, Kreuz M, Bug S, Vater I, et al. High resolution SNP array genomic profiling of peripheral $\mathrm{T}$ cell lymphomas, not otherwise specified, identifies a subgroup with chromosomal aberrations affecting the REL locus. Br J Haematol. 2010;148:402-12.

58. Nelson M, Horsman DE, Weisenburger DD, Gascoyne RD, Dave BJ, Loberiza FR. Cytogenetic abnormalities and clinical correlations in peripheral T-cell lymphoma. $\mathrm{Br} \mathrm{J}$ Haematol. 2008;141:461-9.

59. Nakagawa M, Nakagawa-Oshiro A, Karnan S, Tagawa H, Utsunomiya A, Nakamura S. Array comparative genomic hybridization analysis of PTCL-U reveals a distinct subgroup with genetic alterations similar to lymphoma-type adult T-cell leukemia/lymphoma. Clin Cancer Res. 2009;15:30-8.

60. Martinez-Delgado B. Peripheral T-cell lymphoma gene expression profiles. Hematol Oncol. 2006;24:113-9.

61. Martinez-Delgado B, Cuadros M, Honrado E, Ruiz de la Parte A, Roncador G, Alves J, et al. Differential expression of NF-kappaB pathway genes among peripheral $\mathrm{T}$-cell lymphomas. Leukemia. 2005; 19:2254-63.

62. Ballester B, Ramuz O, Gisselbrecht C, Doucet G, Loi L, Loriod $\mathrm{B}$, et al. Gene expression profiling identifies molecular subgroups among nodal peripheral T-cell lymphomas. Oncogene. 2006;25: 1560-70.

63. Cuadros M, Dave SS, Jaffe ES, Honrado E, Milne R, Alves J, et al. Identification of a proliferation signature related to survival in nodal peripheral T-cell lymphomas. J Clin Oncol. 2007;25: 3321-9.

64. Streubel B, Vinatzer U, Willheim M, Chott A. Novel $\mathrm{t}(5 ; 9)(\mathrm{q} 33 ; \mathrm{q} 22)$ fuses ITK to SYK in unspecified peripheral T-cell lymphoma. Leukemia. 2006;20:313-8.

65. Huang Y, Moreau A, Dupuis J, Streubel B, Petit B, Le Gouill S, et al. Peripheral T-cell lymphomas with a follicular growth pattern are derived from follicular helper T cells (TFH) and may show overlapping features with angioimmunoblastic T-cell lymphomas. Am J Surg Pathol. 2009;33:682-90.

66. Turner SD. Inimitable Imatinib: the range of targeted tumours expands to include T-cell lymphoma. Leukemia. 2013;27:759.

67. Coiffier B, Pro B, Prince M, et al. Final results from a pivotal, multicenter, international open-label, phase 2 study of Romidepsin in progressive or relapsed peripheral T-cell lymphoma (PTCL) following prior systemic therapy. J Clin Oncol. 2012;30:631-6.

68. Mahadevan D, Spier C, Della Croce K, Miller S, George B, Riley $\mathrm{C}$, et al. Transcript profiling in peripheral T-cell lymphoma, not otherwise specified, and diffuse large B-cell lymphoma identifies distinct tumor profile signatures. Mol Cancer Ther. 2005;4: 1867-79.

69. Iqbal J, Weisenburger DD, Chowdhury A, Tsai MY, Srivastava G, Greiner TC, et al. Natural killer cell lymphoma shares strikingly similar molecular features with a group of non-hepatosplenic gamma/delta T-cell lymphoma and is highly sensitive to a novel aurora kinase A inhibitor in vitro. Leukemia. 2011;25: 348-58.

70. Qia W, Spiera C, Liua X, Agarwala A, Cookea LS, Perskyb DO, et al. Alisertib (MLN8237) an investigational agent suppresses Aurora A and B activity, inhibits proliferation, promotes endoreduplication and induces apoptosis in T-NHL cell lines 
supporting its importance in PTCL treatment. Leuk Res. 2013;37:434-9.

71. Friedberg JW, Mahadevan D, Cebula E, Persky D, Lossos I, Agarwal AB, et al. Phase II study of Alisertib, a selective AuroraKinase inhibitor, in relapsed and refractory aggressive B- and T-cell non-Hodgkin lymphomas. J Clin Oncol. 2013 (Epub ahead of print).
72. Ferrando AA, et al. 55th ASH annual meeting and exposition. Blood. 2013;122:811.

73. Piccaluga PP, Agostinelli C, Tripodo C, Gazzola A, Bacci F, Sabattini E, Pileri SA. Peripheral T-cell lymphoma classification: the matter of cellular derivation. Expert Rev Hematol. 2011;4(4):415-25. 